\title{
A FRACTAL ANALYSIS FOR NET PRESENT VALUE OF MULTI-STAGE HYDRAULIC FRACTURED HORIZONTAL WELL
}

\author{
HONG-LIN LU, $,, \S, \|$ JI-JUN ZHANG, ${ }^{*}$ XIAO-HUA TAN,,${ }^{\dagger, \boldsymbol{q}, \|}$ \\ XIAO-PING LI $^{\dagger}$ and JIA-HUI ZHAO ${ }^{\ddagger}$ \\ ${ }^{*}$ School of Economics and Management \\ Southwest Petroleum University, P. R. China \\ ${ }^{\dagger}$ State Key Laboratory of Oil and Gas Reservoir Geology and Exploitation \\ Southwest Petroleum University, P. R. China \\ ${ }^{\ddagger} B o b$ L. Herd Department of Petroleum Engineering \\ Texas Tech University, USA \\ \$yhdx009@qq.com \\ 『xiaohua-tan@163.com
}

Received February 23, 2017

Revised April 13, 2017

Accepted April 17, 2017

Published June 5, 2017

\begin{abstract}
Because of the low permeability, multi-stage hydraulic fractured horizontal wells (MHFHWs) occupy a dominant position among production wells in tight gas reservoir. However, net present value (NPV) estimation method for MHFHW in tight gas reservoirs often ignores the effect of heterogeneity in microscopic pore structure. Apart from that, a new fractal model is presented for NPV of MHFHW, based on the fractal expressions of formation parameters. First, with the aid of apparent permeability model, a pseudo pressure expression considering both reservoir fractal features and slippage effect is derived, contributing to establish the productivity model.
\end{abstract}

\footnotetext{
" Corresponding authors.

This is an Open Access article published by World Scientific Publishing Company. It is distributed under the terms of the Creative Commons Attribution 4.0 (CC-BY) License. Further distribution of this work is permitted, provided the original work is properly cited.
} 
Secondly, economic assessment method is built based on the fractal productivity model, in order to obtain the NPV of MHFHW. Thirdly, the type curves are illustrated and the influences of different fractal parameters are discussed. The pore fractal dimensions $D_{f}$ and the capillary tortuosity fractal dimensions $D_{T}$ have significant effects on the NPV of an MHFHW. Finally, the proposed model in this paper provides a new methodology for analyzing and predicting the NPV of an MHFHW and may be conducive to a better understanding of the optimal design of MHFHW.

Keywords: Fractal Analysis; Net Present Value; Multi-Stage Hydraulic Fractured Horizontal Well; Fractal Productivity Model; Horizontal Well Economic Length.

\section{INTRODUCTION}

Petit et al! presented economic models to calculate the cost of oil production of steam injection with horizontal wells. These models, which were utilized to rate technical and economic performances of steam drive according to the reservoir properties and spatial distributions for vertical and horizontal wells, were helpful for the optimization of economic cost. Based on horizontal well technology, an economic model for evaluating the feasibility of developing naturally fractured reservoirs was proposed by .Guo and Evans. ${ }^{2}$ Engineers comparing the production and economic performance profiles can make using this model the optimizing choice of horizontal well drilling system from various schemes. Smith et al! 3 pointed out the economic risk if the areal anisotropy of horizontal permeability was neglected. The incremental deviation from the best orientation would encourage a decline in the net present value (NPV). To rate whether the solvent-assisted process for the exploitation of reservoirs, which can be exploited by cold production or by thermal methods, was economic or not, Frauenfeld et al. $\stackrel{4}{ }$ used some partially scaled physical model to imitate this process. Consequently, they found the optimum scenarios for various reservoir conditions. Komery et al! $!^{5}$ proposed several critical concepts to develop bitumen economically based on SAGD technology.

Comparing the total costs of the horizontal well drilled from the surface and from underground tunnel, they hold that the revenue of surface drilled one was more. A comprehensive method was represented by $\mathrm{Cho}^{6}$ to analyze the parameters that have an effect on the productivity and overall economics. This approach can be used to optimize the economic length of horizontal well. Edmunds and Chhina ${ }^{7}$ presented the evidence to confirm the best economic operating pressure for the steam-assisted gravity drainage in Alberta. As a result, they concluded the economic sensitivity preference, such as steam/oil ration and resource quality, of the SAGD project. Wright ${ }^{8}$ researched three areas for the investigation of economic feasibility. Results from his study presented the costs of wells at an ultimate recovery and were more sensitive to capital costs and gas prices than operating prices. To optimize the economics of the horizontal well scenarios so that the completion and stimulation project matched the goal of this plan, Britt and Smith ${ }^{9}$ executed some researches. It can be concluded from the studies that comprehensive well-planed horizontal well scenarios resulted in success and economic profit, and the risk mitigation strategies should be the priority of designing a horizontal well project. Yang et al ${ }^{10}$ adopted a series of approach to model the SAGD operation in order to acquire the economic optimization and uncertainty evaluation. It is noteworthy that the SAGD design parameter is a crucial factor to the NPV.

For the optimum design of horizontal well and hydraulic fracture, Bagherian et al. 11 analyzed various sensitivities of parameters of the horizontal well coupled with the assessment of economic. As they put it, the optimization was critical and necessary to each specific reservoir, and uniform solution of all kinds of reservoirs was impossible. Mendoza et al! 12 described the procedure of how to execute a completion design of horizontal well and hydraulic fracture, the stages of fracture and assessment of economic included. This workflow, available to obtain the key properties of reservoir, provided a quantitative approach to optimize the shale reservoirs. The economic operating envelope of Haynesville and the profitability on the basis of production and economic assessment were described by Kaiser ${ }^{13}$ As a result, the price sensitivity and economic feasibility were inspected. Kaiser ${ }^{14}$ utilized the type curves to perform the investigation of two-variable factor model and developed the relation of pre-tax and 
post-tax. The consequence of this exploration indicated that well profitability was vulnerable to the gas price fluctuation. According to various productivities of the Barnett Shale wells and diversity of Btu, the economics of drilling new wells of the play was assessed by Gülen et al ${ }^{15}$ Based on the evaluation, both dry gas and high Btu wells are sensitive to the price fluctuation of oil and gas.

Because of the low permeability, multi-stage hydraulic fractured horizontal wells (MHFHWs) occupy a dominant position among production wells in tight gas reservoir. However, NPV estimation method for MHFHW in tight gas reservoirs often ignores the effect of heterogeneity in microscopic pore structure. Apart from that, a new fractal model is presented for NPV of MHFHW, based on the fractal expressions of formation parameters.

Fractal theory has been used to describe kinds of physical phenomenon in porous media, $\frac{16,25}{25}$ such as the seepage characters of transient flow, 26-28 capillary imbibition, 29130 non-Darcy flow, 313 thermal conductivity. ${ }^{34}$ and multiphase flow ${ }^{28} \mathrm{Xu}$ et al. ${ }^{\sqrt{35}}$ presented a tree-shaped fractal flow model that considered the dynamic behavior of branching tubes in a tree-shaped fractal network and analyzed the mass transport property of this model. The models and results might be helpful for understanding the transport properties in the network structures. Gosselin ${ }^{36}$ minimized the pumping power requirement in a fluid tree-shaped network under different size constraints and optimized the tree-shaped fluid networks with size limitations. In the end, he extended the global cost minimization approach to the design of a porous architecture and provided fundamental tools for the designers of fluid tree-shaped networks. The radial flow regime tending to well bottom is of great significance in the underground seepage and oil exploitation field. Because tree-shaped fractal network has a great advantage on simulation of radial flow, Tan and Li37 embedded a treeshaped fractal network into a matrix system and researched the transient flow and pressure dynamic features in multi-porosity porous media. The mass and heat transfer in tree-shaped network have been study widely, $\stackrel{38}{,}$ but the power-law fluids flow in treeshaped network, especially unsteady flow, need to be researched carefully. In this paper, we will try to establish the model of NPV and optimize the horizontal well economic length of horizontal well, combining the economic evaluation method and formation model with fractal character.

\section{FRACTAL MODEL FOR NPV}

\subsection{Physical Model and Assumptions}

What is portrayed in Fig. 1 is the physical model of MHFHWs of gas reservoir whose assumption is as follows.

(1) The horizontal thickness, $h$, of reservoir stratum is isopachous. Both the top and the bottom of the reservoir are sealed. The initial formation pressure is $P_{e}$ and the formation temperature is fixed, $T$. The length of the horizontal section of MHFHW is $L$, which is located in the middle of the reservoir stratum and paralled with the boundary of the top and bottom of reservoir stratum.

(2) The completion method of the well is preformation completion and no perforation is added to the horizontal section. Besides, the productivity of MHFHWs is completely provided by the hydraulic created fractures, which are artificial transverse cracks of equal length.

(3) The penetration of gas in the reservoir stratum and artificial cracks is single-phase isothermal steady flow.

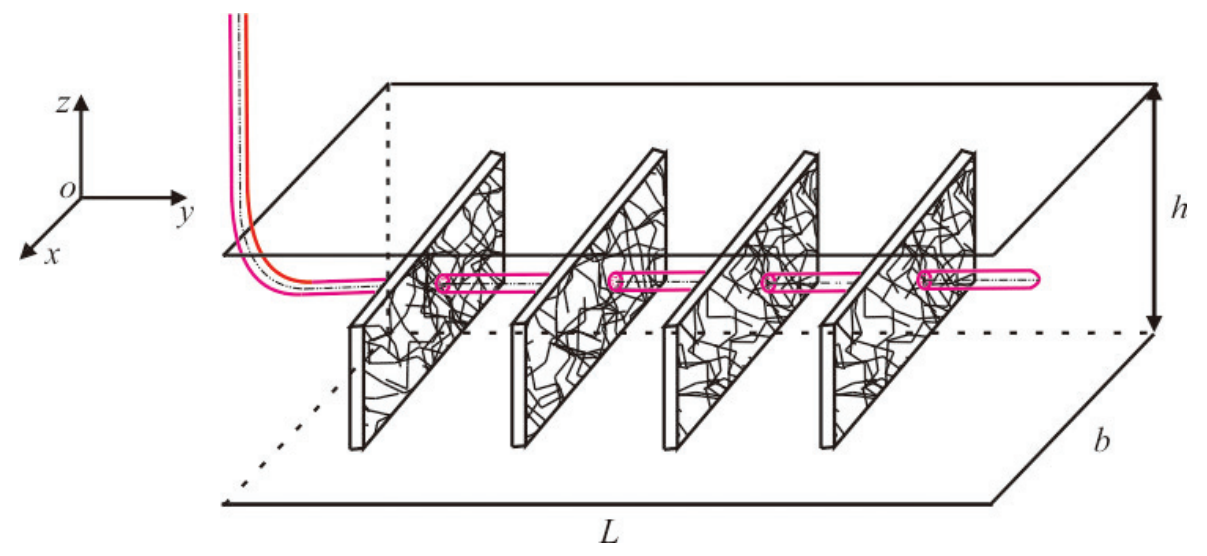

Fig. 1 The physical model of MHFHW. 


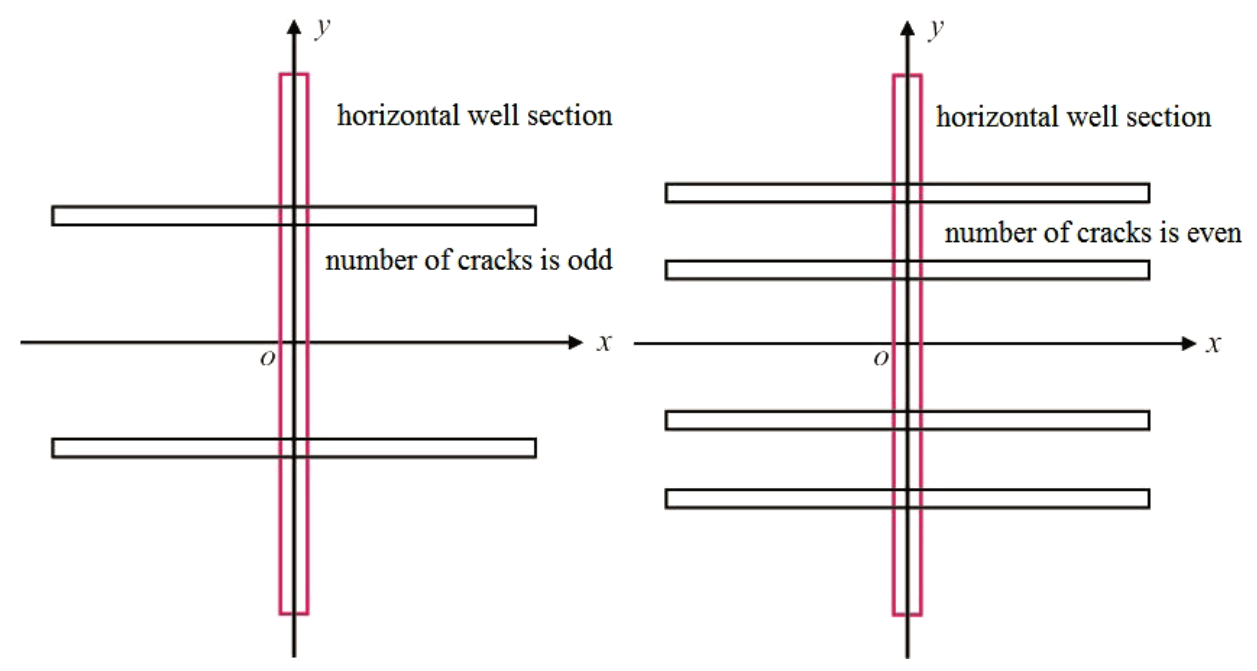

Fig. 2 The distribution of cracks of fractured horizontal well.

(4) Regardless of skin effect, neglect the effect of gravity and capillary force.

\subsection{The Productivity Equation of Fractured Horizontal Well}

Figure 2 is a planform of Fig. 1] According to whether the number of cracks is odd or not, the distribution of cracks of fractured is depicted as Fig. 2, for the parity of the number of cracks has an effect on the mathematical law 39

Conformal transformation refers to the alternation of seepage problem in complex area to the seepage problem in simple area, selecting proper conformal transformation function like Eq. (1) is introduced to deal with the seepage problem of complex penetration area that the equipotential line around hydraulic fractured cracks is elliptical. As is illustrated in Fig. 3, the upper semi-ellipse of $Z_{1}$ plane is transformed into infinite plane whose width is $\pi$ on the right of $Z_{2}$ plane, whereas the lower semi-ellipse is the one on the left. Meanwhile, the hydraulic fractured cracks with a length of $2 X_{f}$ are transformed into drainage tunnel with a width. $\underline{40}$

$$
\begin{aligned}
& Z_{1}=X_{f} \cosh Z_{2}, \\
& Z_{1}=x+i y, \quad Z_{2}=u+i v,
\end{aligned}
$$

where $X_{f}$ is the half length of fracture.

Separate the real and imaginary parts of conformal transformation of Eq. (1):

$$
\left\{\begin{array}{l}
x=X_{f} \operatorname{ch} u \cdot \cos v \\
y=X_{f} \operatorname{sh} u \cdot \sin v
\end{array} .\right.
$$

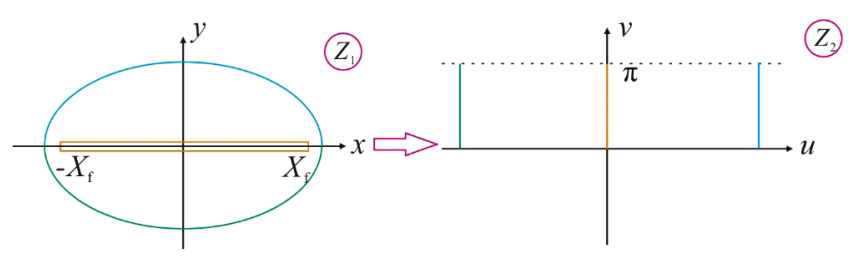

Fig. 3 The conformal transformation of cracks of fractured horizontal well.

Based on the properties of hyperbolic sine and hyperbolic cosine,

$$
\begin{aligned}
u= & \operatorname{arch} \frac{1}{\sqrt{2}}\left[1+\frac{x^{2}+y^{2}}{X_{f}^{2}}\right. \\
& \left.+\sqrt{1+\frac{x^{2}+y^{2}}{X_{f}^{2}}}-\frac{4 x^{2}}{X_{f}^{2}}\right]^{0.5} .
\end{aligned}
$$

The potential distribution function of any point of $Z_{2}$ plane can be expressed as 41 :

$$
\Phi(x, y)=\frac{q_{\mathrm{gscf}} B_{g}}{2 \pi h} u+C,
$$

where $\Phi(x, y)$ is the potential distribution function of any point, $q_{\mathrm{gscf}}$ the surface flow rate of a single fracture, $B_{g}$ the gas formation volume factor, $h$ the effective thickness of reservoir stratum and $C$ a constant.

Inserting Eq. (44) into Eq. (5)

$$
\begin{aligned}
\Phi(x, y)= & \frac{q_{\mathrm{gscf}} B_{g}}{2 \pi h} \operatorname{arch} \frac{1}{\sqrt{2}}\left[1+\frac{x^{2}+y^{2}}{X_{f}^{2}}\right. \\
& \left.+\sqrt{1+\frac{x^{2}+y^{2}}{X_{f}^{2}}-\frac{4 x^{2}}{X_{f}^{2}}}\right]^{0.5}+C .
\end{aligned}
$$


What can be apparently seen from Fig. 2 is that no matter whether the number of fractures is odd or even, the coordinate formula of the midpoint of fracture is $\left(0, y_{0}\right)$. As a result, Eq. (6) can be expressed as follows:

$$
\begin{aligned}
\Phi(x, y)= & \frac{q_{\mathrm{gscf}} B_{g}}{2 \pi h} \operatorname{arch} \frac{1}{\sqrt{2}}\left[1+\frac{x^{2}+\left(y_{0}-y\right)^{2}}{X_{f}^{2}}\right. \\
& \left.+\sqrt{1+\frac{x^{2}+\left(y_{0}-y\right)^{2}}{X_{f}}}-\frac{4 x^{2}}{X_{f}}\right]^{0.5}+C .
\end{aligned}
$$

Assume that

$$
\begin{aligned}
& \eta= \operatorname{arch} \frac{1}{\sqrt{2}}\left\{1+\frac{x^{2}}{X_{f}^{2}}+\left(\frac{y_{0}}{X_{f}}-\frac{y}{X_{f}}\right)^{2}\right. \\
&+\sqrt{\left.\left[1+\frac{x^{2}}{X_{f}^{2}}+\frac{\left(y_{0}-y\right)^{2}}{X_{f}^{2}}\right]^{2}-4 \frac{x^{2}}{X_{f}^{2}}\right\}^{0.5},} \\
& B_{g}=\frac{Z T}{p} \frac{p_{\mathrm{sc}}}{T_{\mathrm{sc}}}
\end{aligned}
$$

Substitute the above formula into the formula of gas formation volume factor. Thus Eq. (7) can be rewritten as

$$
\Phi(x, y)=\frac{q_{\mathrm{gscf}} Z T}{2 \pi p h} \frac{p_{\mathrm{sc}}}{T_{\mathrm{sc}}} \operatorname{arch} \eta+C,
$$

where $p$ is the pressure of any point of reservoir stratum. $Z$ represents the gas deviation factor, which is dimensionless. $T$ is the temperature of reservoir stratum. $p_{\mathrm{sc}}$ represents the gas pressure under normal temperature pressure (NTP), $0.101 \mathrm{MPa} . T_{\mathrm{sc}}$ is the gas temperature under NTP, $293.15 \mathrm{~K}$.

Based on the definition of potential distribution function $\Phi=\left(K / \mu_{g}\right) p$, rewrite Eq. (8) as the pressure form:

$$
p(x, y)=\frac{q_{\mathrm{gscf}} T}{2 \pi K h} \frac{p_{\mathrm{sc}}}{T_{\mathrm{sc}}} \frac{\mu_{g} Z}{p} \operatorname{arch} \eta+C,
$$

where $p(x, y)$ is the pressure distribution function of any point of reservoir stratum, $\mu_{g}$ the gas viscosity and $K$ the formation permeability.

According to the foregoing chapter, the pore throats size of reservoir stratum of gas reservoir is very small, and the slippage effect on gas penetration in reservoir stratum should be taken into consideration. Therefore, insert the apparent permeability proposed by Zheng et al. ${ }^{42}$ formula into Eq. (9), separate the variables and differentiate

$$
\begin{aligned}
(1+ & \left.\frac{8\left(3+D_{t}-D_{f}\right)}{\lambda_{\max }\left(2+D_{t}-D_{f}\right)} \frac{\mu_{g}}{p} \sqrt{\frac{\pi R T}{2 M}}\right) \frac{p}{\mu_{g} Z} \mathrm{~d} p \\
& =\frac{q_{\mathrm{gscf}} T}{2 \pi K_{\infty} h} \frac{p_{\mathrm{sc}}}{T_{\mathrm{sc}}} \mathrm{d} \eta
\end{aligned}
$$

where $\lambda_{\max }$ is the maximum diameter in matrix, $D_{f}$ the pore fractal dimensions of matrix that represents the relationship between the pore number and the character length. $D_{T}$ is the capillary tortuosity fractal dimension that represents relationship between the flow distance and the character length. $M$ is the molecular mass, $K_{\infty}$ the gas apparent permeability and $R$ the universal gas constant.

Define the gas pseudo pressure formula, considering the fractal traits of reservoir stratum capillary and slippage effect, as

$$
\begin{aligned}
m(p)= & \int_{p_{s c}}^{p}\left[1+\frac{8\left(3+D_{t}-D_{f}\right)}{\lambda_{\max }\left(2+D_{t}-D_{t}\right)} \frac{\mu_{g}}{p} \sqrt{\frac{\pi R T}{2 \gamma_{g} M_{\text {air }}}}\right] \\
& \times \frac{p}{\mu_{g} Z} \mathrm{~d} p,
\end{aligned}
$$

where $r_{g}$ is the gas relative density and $M_{\text {air }}$ is the molecular mass of air.

Based on Eq. (11), when the other parameters are fixed, and the radius of pore tends to infinity, which means that the size of passageway is far greater than the size of gas itself, Eq. (11) can degenerate into gas pseudo pressure expression, regardless of slippage effect. However, when the other parameters are fixed, the slippage effect becomes more obvious as the pressure decreases. Thus, the slippage effect on gas pseudo pressure should be taken into consideration.

Substituting Eq. (11) into Eq. (10) and integrating both sides of the obtained equation in the corresponding interval gives

$$
\begin{aligned}
m(x, y)= & \frac{q_{\mathrm{gsc}} T}{2 \pi K_{\infty} h} \frac{p_{\mathrm{sc}}}{T_{\mathrm{sc}}} \operatorname{arch} \frac{1}{\sqrt{2}} \\
& \times\left\{1+\frac{x^{2}}{X_{f}^{2}}+\left(\frac{y_{0}}{X_{f}}-\frac{y}{X_{f}}\right)^{2}\right. \\
& \left.+\sqrt{\left[1+\frac{x^{2}}{X_{f}^{2}}+\frac{\left(y_{0}-y\right)^{2}}{X_{f}^{2}}\right]^{2}-4 \frac{x^{2}}{X_{f}^{2}}}\right\} \\
& +C .
\end{aligned}
$$


Equation (12) is the pseudo pressure distribution expression of single fracture on the plane, considering the fractal properties of pores of gas reservoir stratum and gas slippage effect.

In consideration of the mutual interference of each crack on the plane and based on the superposition principle of potential, the pseudo pressure distribution when $N$ cracks simultaneously bring into production can be expressed as:

$$
\begin{aligned}
m(x, y)= & \frac{T}{2 \pi K_{\infty} h} \frac{p_{\mathrm{sc}}}{T_{\mathrm{sc}}} \sum_{i=-N_{0}}^{N_{0}} q_{\mathrm{gsc} i} \operatorname{arch} \frac{1}{\sqrt{2}} \\
& \times\left\{1+\frac{x^{2}}{X_{f}^{2}}+\left(\frac{y_{0}}{X_{f}}-\frac{y}{X_{f}}\right)^{2}\right. \\
& \left.+\sqrt{\left[1+\frac{x^{2}}{X_{f}^{2}}+\frac{\left(y_{0}-y\right)^{2}}{X_{f}^{2}}\right]^{2}-4 \frac{x^{2}}{X_{f}^{2}}}\right\}^{0.5} \\
& +C_{1} .
\end{aligned}
$$

When the crack number of fractured horizontal well is odd, $i$ increases from $-N_{0}$ at a rate of 1 . However, when the crack number of fractured horizontal well is even, $i$ from $-N_{0}$ at a rate of 2 , and the spacing $d$ and half spacing $N_{0}$ can be expressed as:

$$
d=\left\{\begin{array}{l}
L / N \\
L /(2 N)
\end{array}, \quad N_{0}=\left\{\begin{array}{ll}
(N-1) / 2, & N \text { is odd } \\
N-1, & N \text { is even }
\end{array} .\right.\right.
$$

The pseudo pressure of crack $J$ is as follows:

$$
\begin{aligned}
m(0, n d)= & \frac{T}{2 \pi K_{\infty} h} \frac{p_{\mathrm{sc}}}{T_{\mathrm{sc}}} \sum_{i=-N_{0}}^{N_{0}} q_{\mathrm{gsc} i} \operatorname{arch} \\
& \times \sqrt{1+\frac{(n d-i d)^{2}}{X_{f}^{2}}}+C_{1},
\end{aligned}
$$

where

$$
n=\left\{\begin{array}{ll}
-N_{0}+j-1, & N \text { is odd } \\
-N_{0}+2(j-1), & N \text { is even }
\end{array} .\right.
$$

The pseudo pressure of crack of gas drainage radius is

$$
\begin{aligned}
m\left(0, r_{e}\right)= & \frac{T}{2 \pi K_{\infty} h} \frac{p_{\mathrm{sc}}}{T_{\mathrm{sc}}} \sum_{i=-N_{0}}^{N_{0}} q_{\mathrm{gsc} i} \operatorname{arch} \\
& \times \sqrt{1+\frac{\left(r_{e}-i d\right)^{2}}{X_{f}^{2}}}+C_{1},
\end{aligned}
$$

where $r_{e}$ is the gas drainage radius of the gas reservoir.

In order to eliminate the constant $C_{1}$, Eq. (17) minus Eq. (15) gives

$$
\begin{aligned}
m\left(0, r_{e}\right)-m(0, n d)= & \frac{T}{2 \pi K_{\infty} h} \frac{p_{\mathrm{sc}}}{T_{\mathrm{sc}}} \sum_{i=-N_{0}}^{N_{0}} q_{\mathrm{gsc} i} \\
& \times\left[\operatorname{arch} \sqrt{1+\frac{\left(r_{e}-i d\right)^{2}}{X_{f}^{2}}}\right. \\
& \left.-\operatorname{arch} \sqrt{1+\frac{(n d-i d)^{2}}{X_{f}^{2}}}\right] .
\end{aligned}
$$

Inverse hyperbolic cosine function has the following property:

$$
\operatorname{arch} \sqrt{1+x^{2}}=\ln \left(x+\sqrt{1+x^{2}}\right) .
$$

Based on Eq. (19), Eq. (18) can be simplified as:

$$
\begin{aligned}
& m\left(0, r_{e}\right)-m(0, n d)=\frac{T}{2 \pi K_{\infty} h} \frac{p_{\mathrm{sc}}}{T_{\mathrm{sc}}} \\
& \times \sum_{i=-N_{0}}^{N_{0}} q_{\mathrm{gscf} i} \ln \left(r_{e}-i d / X_{f}\right) \\
&+\sqrt{1+\left(r_{e}-i d\right)^{2} / X_{f}^{2}}\left|\frac{n d-i d}{X_{f}}\right| \\
&+\sqrt{1+\left((n d-i d)^{2} / X_{f}^{2}\right)} .
\end{aligned}
$$

The derivation of the above formula is based on the SI basic unit system. Convert the unit system of Eq. (20) into SI field unit system to facilitate example calculation and substitute the standard pressure, standard temperature and circular constant into the obtained equation, Eq. (20) will be simplified as:

$$
\begin{aligned}
m\left(0, r_{e}\right)-m(0, n d) & \\
= & \frac{6.37 \times 10^{-4} T}{K_{\infty} h} \sum_{i=-N_{0}}^{N_{0}} q_{\mathrm{gsc} f i} \ln \\
& \times \frac{\left(r_{e}-i d / X_{f}\right)+\sqrt{1+\left(r_{e}-i d\right)^{2} / X_{f}^{2}}}{\left|\frac{n d-i d}{X_{f}}\right|+\sqrt{1+(n d-i d)^{2} / X_{f}^{2}}},
\end{aligned}
$$

where $q_{\mathrm{gsc} f i}$ is the surface production rate of crack $i$.

During the process of gas flowing from fractures into the wellbore of fractured horizontal well, at 


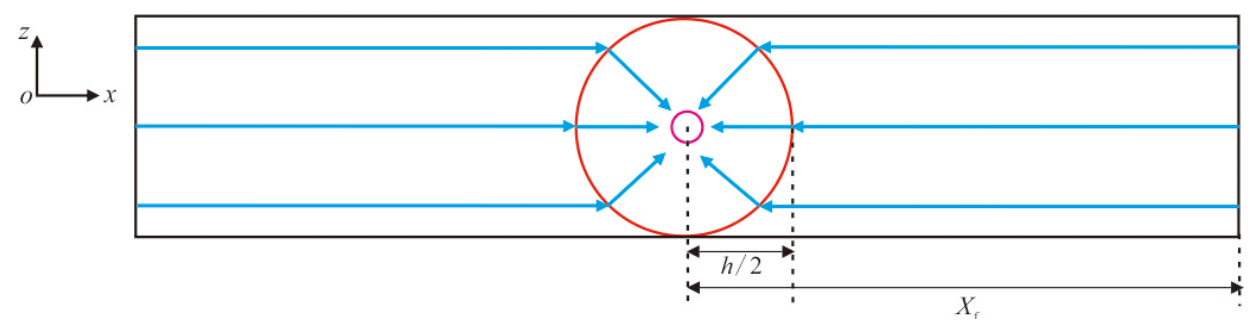

Fig. 4 Gas penetration in a crack.

first, the gas flows from the crack tip into the crack region of near wellbore in a pattern of linear flow, which is called confluence effect. Then the gas flows from the crack region near wellbore into the wellbore in a pattern of radial flow penetration.

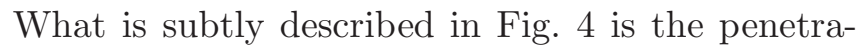
tion region of gas in a crack. As can be apparently seen from this graph, the linear flow penetration region is $h / 2<x<X_{f}$ and the radial flow region is $r_{w}<x<h / 2$.

The linear seepage equation of gas flowing from the crack tip to the region near wellbore is 43

$$
\frac{\mathrm{d} p}{\mathrm{~d} x}=-\frac{\mu_{g}}{K_{f i}} v_{g},
$$

where $K_{f i}$ represents the permeability of crack $i$ and $v_{g}$ is the seepage velocity.

Rewrite Eq. (22) into volume flow rate form, insert the obtained outcome into the formula of gas formation volume factor $B_{g}$, and separate the variables.

$$
\frac{p}{\mu_{g} Z} \mathrm{~d} p=-\frac{q_{\mathrm{gsc} j} T}{K_{f i} \omega_{f} h} \frac{p_{\mathrm{sc}}}{T_{\mathrm{sc}}} \mathrm{d} x,
$$

where $q_{\mathrm{gscf} j}$ is the surface production rate of crack $j$ and $\omega_{f}$ is the width of the crack.

Define the gas pseudo pressure function of the fractured crack as

$$
m^{\prime}(p)=\int_{p_{\mathrm{sc}}}^{p} \frac{p}{\mu_{g} Z} d p .
$$

Integrate both sides of Eq. (23) in the corresponding interval and insert the obtained outcome into Eq. (24)

$$
\begin{aligned}
& m^{\prime}\left(p_{f j}\right)-m^{\prime}\left(p_{h j}\right) \\
& \quad=\int_{p_{\mathrm{h} j}}^{p_{\mathrm{f} j}} \frac{p}{\mu_{g} Z} \mathrm{~d} p=\frac{q_{\mathrm{gsc} j} T}{K_{f i} \omega_{f} h} \frac{p_{\mathrm{sc}}}{T_{\mathrm{sc}}}\left(X_{f}-\frac{h}{2}\right) .
\end{aligned}
$$

Because of the low pressure of the area near wellbore and the high speed of gas, the non-Darcy effect of high velocity should be taken into consideration in the radial flow of gas in the cracks of the region near wellbore, and the equation of motion is obtained as 4445

$$
\frac{\mathrm{d} p}{\mathrm{~d} r}=\frac{\mu_{g}}{K_{f i}} v_{g}+\beta_{g} \rho_{g} v_{g}^{2},
$$

where

$$
\begin{aligned}
\rho_{g} & =\frac{p M_{\mathrm{air}} \gamma_{g}}{Z R T}, \\
\beta_{g} & =\frac{7.644 \times 10^{10}}{K_{f i}^{1.5}},
\end{aligned}
$$

where $\beta_{g}$ is the turbulent coefficient of gas, $\rho_{g}$ the density of natural gas, $M_{\text {air }}$ the apparent relative molecular mass of air and $\gamma_{g}$ the relative density of natural gas, respectively.

Insert Eq. (27) into Eq. (26) as well as the formula of gas formation volume factor $B_{g}$. Then rewrite the production rate as surface production rate and separate the variables

$$
\begin{aligned}
\frac{p}{\mu_{g} Z} \mathrm{~d} p= & \frac{p_{\mathrm{sc}}}{2 \pi T_{\mathrm{sc}}} \frac{q_{\mathrm{gscf} j} T}{K_{f i} w_{f}} \frac{1}{r} \mathrm{~d} r \\
& +\frac{\beta_{g} M_{\mathrm{air}} p_{\mathrm{sc}}^{2}}{4 \pi^{2} R T_{\mathrm{sc}}^{2} \bar{\mu}_{g}} \frac{q_{\mathrm{gsc} j}^{2} T \gamma_{g}}{w_{f}^{2}} \frac{1}{r^{2}} \mathrm{~d} r,
\end{aligned}
$$

where $\overline{\mu_{g}}$ is the average gas viscosity.

Integrate both sides of Eq. (29) in the corresponding interval and insert the results into Eq. (24)

$$
\begin{aligned}
m^{\prime}\left(p_{h j}\right)-m^{\prime}\left(p_{w f j}\right)= & \frac{p_{\mathrm{sc}}}{2 \pi T_{\mathrm{sc}}} \frac{q_{\mathrm{gsc} j} T}{K_{f i} w_{f}} \ln \frac{h}{2 r_{w}} \\
& +\frac{\beta_{g} M_{\mathrm{air}} p_{\mathrm{sc}}^{2}}{4 \pi^{2} R T_{\mathrm{sc}}^{2} \overline{\mu_{g}}} \frac{q_{\mathrm{gsc} j}^{2} T \gamma_{g}}{w_{f}^{2}} \\
& \times\left(\frac{1}{r_{w}}-\frac{2}{h}\right) .
\end{aligned}
$$


Take the sum of Eqs. (25) and (30)

$$
\begin{aligned}
& m^{\prime}\left(p_{f j}\right)-m^{\prime}\left(p_{w f j}\right) \\
& =\frac{q_{\mathrm{gsc} j} T}{K_{f i} w_{f}} \frac{p_{\mathrm{sc}}}{T_{\mathrm{sc}}}\left[\frac{X_{f}-h / 2}{h}+\frac{1}{2 \pi} \ln \frac{h}{2 r_{w}}\right] \\
& \quad+\frac{M_{\mathrm{air}} p_{\mathrm{sc}}^{2}}{4 \pi^{2} R T_{\mathrm{sc}}^{2} \overline{\mu_{g}}} \frac{\beta_{g} T \gamma_{g} q_{\mathrm{gsc} j}^{2}}{w_{f}^{2}}\left(\frac{1}{r_{w}}-\frac{2}{h}\right) .
\end{aligned}
$$

The derivation of the above formula is based on the SI basic unit system. Convert the unit system of Eq. (31) into SI field unit system to facilitate example calculation and substitute the results as well as the standard pressure, standard temperature, circular constant, gas constant and apparent relative molecular mass of air into Eq. (28):

$$
\begin{aligned}
m^{\prime}\left(p_{f j}\right)-m^{\prime}\left(p_{w f j}\right) & \\
= & \frac{4 \times 10^{-3} T}{K_{f i} w_{f}}\left[\frac{X_{f}-h / 2}{h}+0.16 \ln \frac{h}{2 r_{w}}\right] q_{\mathrm{gsc} j} \\
& +\frac{1.08 \times 10^{-13} T \gamma_{g}}{K_{f i}^{1.5} w_{f}^{2} \overline{\mu_{g}}}\left(\frac{1}{r_{w}}-\frac{2}{h}\right) q_{\mathrm{gscf} j}^{2} .
\end{aligned}
$$

As for each crack, $p_{w f j}$ equals $p_{w f}$, neglecting the wellbore pressure drop. Therefore, a system of non-linear equations comprising $2 N$ unknowns and $2 N$ equations is obtained by combining Eqs. (21) and (32). As is shown in Eq. (33), the production rate of each crack and gross production rate of fractured horizontal well can be acquired by adopting the Newton iteration method.

$$
\left\{\begin{array}{c}
m\left(p_{e}\right)-m\left(p_{f 1}\right)=\frac{6.37 \times 10^{-4} T}{K_{\infty} h} \sum_{i=-N_{0}}^{N_{0}} q_{\mathrm{gscf} i} \ln \\
\times \frac{r_{e}-i d / X_{f}+\sqrt{1+\left(r_{e}-i d\right)^{2} / X_{f}^{2}}}{\left|\frac{n d-i d}{X_{f}}\right|+\sqrt{1+(n d-i d)^{2} / X_{f}^{2}}} \\
\vdots \\
\begin{array}{rl}
m_{e}\left(p_{e}\right)-m\left(p_{f N}\right)= & \frac{6.37 \times 10^{-4} T}{K_{\infty} h} \sum_{i=-N_{0}}^{N_{0}} q_{\mathrm{gscf} i} \ln
\end{array} \\
\times \frac{r_{e}-i d / X_{f}+\sqrt{1+\left(r_{e}-i d\right)^{2} / X_{f}^{2}}}{\left|\frac{n d-i d}{X_{f}}\right|+\sqrt{1+(n d-i d)^{2} / X_{f}^{2}}} \\
m^{\prime}\left(p_{f 1}\right)-m^{\prime}\left(p_{w f}\right)= \\
\vdots \\
m^{\prime}\left(p_{f N}\right)-q_{\mathrm{gscf} 1}+D q_{\mathrm{gsc} 1}^{2} \\
\vdots
\end{array}\right.
$$

where

$$
\begin{aligned}
& C=\frac{4 \times 10^{-3} T}{K_{f i} w_{f}}\left[\frac{X_{f}-h / 2}{h}+0.16 \ln \frac{h}{2 r_{w}}\right], \\
& D=\frac{1.08 \times 10^{-13} T \gamma_{g}}{K_{f i}^{1.5} w_{f}^{2} \overline{\mu_{g}}}\left(\frac{1}{r_{w}}-\frac{2}{h}\right) .
\end{aligned}
$$

\subsection{Economic Evaluation for MHFHW}

The gross income of the horizontal well production is the gross income of natural gas sales. The gross income of horizontal well production can be expressed as follows: when considering the horizontal well production rate, natural gas sales price and the interest change over time in the production and sales of natural gas 2 :

$$
\begin{aligned}
\mathrm{CI}(t)= & \sum_{j=1}^{t} 0.33\left[Q_{g}\left(1-C_{g}\right)^{j-1} P\left(1+C_{P}\right)^{j-1}\right] \\
& \times \frac{1}{(1+i)^{j-1}},
\end{aligned}
$$

where $\mathrm{CI}(t)$ is the gross income of horizontal well being put into operation for $t$ years. $j$ is the production time of horizontal well. $t$ is the production year of horizontal well, $P$ is the sales price basis of natural gas of the first year. $C_{p}$ is the annual rate of growth of natural gas sales price. $i$ is the bank rate or interest rate. $C_{g}$ is the annual rate of decrease of the production rate of horizontal well.

In Eq. (36), $Q_{g}$ is the benchmark production rate of horizontal well of the first year. $Q_{g}$ is the sum of the production rates of all cracks in MHFHW, $q_{\mathrm{gscf}}$, which can be obtained from Eq. (33). The cost of the development of horizontal well mainly includes the cost of pre-production period and post-production period.

The production costs of horizontal well mainly consist of the expenses of ground construction and that of drilling and completion. The costs of well drilling, well completion and well cementation account for the majority of the investment of horizontal well. However, different structures, profile types, horizontal section lengths and completion method of horizontal well make it hard to precisely estimate the costs of well drilling and completion of horizontal well. Moreover, the accurate assessment of this cost is crucial to correctly evaluate the economic benefits. 
The pre-production cost of horizontal well can be calculated in the following way ${ }^{9}$ :

$$
\begin{aligned}
C_{b}= & C_{\mathrm{gb}}+C_{v} L_{v}+C_{s} L_{s}+C_{\mathrm{hb} 0} L+r_{h} L^{2} \\
& +C_{\mathrm{fb} 0} \frac{L}{L_{n}}+r_{f}\left(\frac{L}{L_{n}}\right)^{2},
\end{aligned}
$$

where $C_{b}$ is the cost of the pre-production period of horizontal well, $C_{\mathrm{gb}}$ the total cost of the ground engineering, $C_{v}$ the well drilling cost of vertical section of the well per meter, $C_{s}$ the well drilling cost of inclined section of the well per meter, $C_{\mathrm{hb} 0}$ the base value of cost of well drilling completion and cementation of horizontal section per meter, $C_{\mathrm{fb} 0}$ the base value of fracturing cost of horizontal well length, $r_{h}$ the cost growth factor of well drilling and completion of horizontal section, $r_{f}$ the fracturing cost growth factor of horizontal well, $L_{v}$ the length of vertical section of well, $L_{s}$ the length of inclined section of well, $L$ the length of horizontal well and $L_{n}$ the horizontal section length of each fractured horizontal well.

On the other hand, the costs of post-production period of horizontal well mainly contain the cost of production and operation, as well as the taxes payable.

Considering whether the production rate of horizontal well, unit production and operation costs and the interest rates change over time or not, the production and operation cost of horizontal well can be expressed as follows 10 ?

$$
\begin{aligned}
C_{p}(t)= & \sum_{j=1}^{t} 0.33 Q_{g}\left(1-C_{g}\right)^{j-1} C_{\mathrm{mg}}\left(1+r_{m}\right)^{j-1} \\
& \times \frac{1}{(1+i)^{j-1}},
\end{aligned}
$$

where $C_{p}(t)$ is the production and operation cost of horizontal well and $C_{\mathrm{mg}}$ the production and operation cost of horizontal well per unit volume gas in the first year. $r_{m}$ is the annual rate of growth of production and operation cost. Considering the production rate of horizontal well, the taxes paid for the horizontal well production and the interest rate change over time or not, the taxes payable for horizontal well production can be expressed as follows10:

$$
\begin{aligned}
C_{s}(t)= & \sum_{j=1}^{t} 0.33 Q_{g}\left(1-C_{g}\right)^{j-1} C_{\operatorname{tax}}\left(1+r_{\text {tax }}\right)^{j-1} \\
& \times \frac{1}{(1+i)^{j-1}}
\end{aligned}
$$

where $C_{\mathrm{S}}(t)$ is the tax payable, $C_{\mathrm{tax}}(t)$ the benchmark consolidated tax of the first year and $r_{\operatorname{tax}}$ the annual rate of growth of consolidated tax.

The gross cost of horizontal well production is

$$
\mathrm{CO}(t)=C_{b}+C_{p}(t)+C_{s}(t)
$$

or

$$
\begin{aligned}
\mathrm{CO}(t)= & C_{\mathrm{gb}}+C_{v} L_{v}+C_{s} L_{s}+C_{\mathrm{hb} 0} L+r_{h} L^{2} \\
& +C_{\mathrm{fb} 0} \frac{L}{L_{n}}+r_{f}\left(\frac{L}{L_{n}}\right)^{2}+C_{p}(t)+C_{s}(t) .
\end{aligned}
$$

During the production period, $t$, the annual rate of decrease of horizontal well production is $C_{g}$, and the NPV can be expressed as

$$
\begin{aligned}
R= & \mathrm{CI}(t)-\mathrm{CO}(t)=\sum_{j=1}^{t} 0.33 Q_{g} \frac{\left(1-C_{g}\right)^{j-1}}{(1+i)^{j-1}} \\
& \times\left\{\left[P\left(1+C_{P}\right)^{j-1}-C_{\mathrm{mg}}\left(1+r_{m}\right)^{j-1}\right.\right. \\
& \left.\left.-C_{\mathrm{tax}}\left(1+r_{\mathrm{tax}}\right)^{j-1}\right]\right\} . \\
& -\left(C_{\mathrm{gb}}+C_{v} L_{v}+C_{s} L_{s}+C_{\mathrm{hb} 0} L+r_{h} L^{2}\right. \\
& \left.+C_{\mathrm{fb} 0} \frac{L}{L_{n}}+r_{f}\left(\frac{L}{L_{n}}\right)^{2}\right) .
\end{aligned}
$$

\section{RESULTS AND DISCUSSION}

Take the MHFHW of a domestic gas field as an example with low permeability, whose development cost and formation parameters are listed in Table 1 . The pore fractal dimensions $D_{f}$ and the capillary tortuosity fractal dimensions $D_{T}$ in Table 1 of matrix in the gas field are obtained by the core test. ${ }^{46}$ The relationship is analyzed among the production rates, net proceeds and the horizontal section length of this well.

What Fig. 5 characterized is the relationship between the net proceeds of natural gas horizontal well and horizontal section length. The net proceeds increases first and the decreases as the horizontal section length increases the net proceed mushroom as the horizontal section length rises with a slowing down increasing amplitude of net proceeds. However, when the increasing amplitude reduces to zero, the net proceeds decrease as the horizontal section length rises with an unceasing increment of decreasing amplitude of net proceeds. As the net proceeds 
Table 1 Parameters for Example Calculation.

\begin{tabular}{|c|c|c|c|}
\hline Parameters & Parameter Symbol & Parameter Unit & Value \\
\hline Production time & $T$ & A & 4 \\
\hline $\begin{array}{l}\text { The annual rate of growth or decrease of horizontal well } \\
\text { production rate }\end{array}$ & $C_{g}$ & & $-30 \%$ \\
\hline The base value of sales price of natural gas in the first year & $P$ & $10^{4} \mathrm{CNY} / 10^{3} \mathrm{~m}^{3}$ & 0.1 \\
\hline The annual rate of growth of natural gas price & $C_{p}$ & & $30 \%$ \\
\hline Benchmark bank rate or interest rate & $I$ & & $15 \%$ \\
\hline The gross cost of surface engineering & $C_{\mathrm{gb}}$ & $10^{4} \mathrm{CNY}$ & 70 \\
\hline The cost of well drilling of vertical well section per meter & $C_{v}$ & $10^{4} \mathrm{CNY} / \mathrm{m}$ & 0.7 \\
\hline Vertical well section length & $L_{v}$ & M & 2540 \\
\hline The cost of well drilling of inclined section per meter & $C_{s}$ & $10^{4} \mathrm{CNY} / \mathrm{m}$ & 1.2 \\
\hline Inclined well section length & $L_{s}$ & $\mathrm{M}$ & 848 \\
\hline $\begin{array}{l}\text { The base value of well drilling, completion and } \\
\text { cementation cost of horizontal section per meter }\end{array}$ & $C_{\mathrm{hb} 0}$ & $10^{4} \mathrm{CNY} / \mathrm{m}$ & 1.2 \\
\hline $\begin{array}{l}\text { The growth factor of well drilling, completion and } \\
\text { cementation cost of horizontal section }\end{array}$ & $r_{h}$ & $\left(10^{4} \mathrm{CNY} / \mathrm{m}\right) / \mathrm{m}$ & 0.0045 \\
\hline $\begin{array}{l}\text { The cost of production and operation in the first year per } \\
\text { unit volume gas }\end{array}$ & $C_{\mathrm{mg}}$ & $10^{4} \mathrm{CNY} / 10^{3} \mathrm{~m}^{3}$ & 0.0138 \\
\hline The annual growth rate of cost of production and operation & $r_{m}$ & & $10 \%$ \\
\hline Benchmark consolidated tax of the first year & $C_{\text {tax }}$ & $10^{4} \mathrm{CNY} / 10^{3} \mathrm{~m}^{3}$ & 0.0085 \\
\hline The growth rate of consolidated tax & $r_{\text {tax }}$ & & $10 \%$ \\
\hline The horizontal well length for each section of fracturing & Ln & $\mathrm{m} /$ section & 250 \\
\hline Cost for each section of fracturing & $C_{\mathrm{fb} 0}$ & $10^{4} \mathrm{CNY} /$ section & 60 \\
\hline Cost growth coefficient for each section of fracturing & $r_{f}$ & $\left(10^{4} \mathrm{CNY} /\right.$ section $) /$ section & 4 \\
\hline The pressure differential of production & $\Delta p$ & $\mathrm{MPa}$ & 5 \\
\hline Natural gas compressibility factors & $Z$ & & 0.95 \\
\hline Relative density of natural gas & $\gamma_{g}$ & & 0.6 \\
\hline The viscosity of natural gas & $\mu_{g}$ & $\mathrm{mPa} \mathrm{s}$ & 0.0192 \\
\hline Formation temperature & $T$ & $\mathrm{~K}$ & 390.15 \\
\hline The wellbore diameter of horizontal well & $D$ & M & 0.1 \\
\hline The wellbore radius of horizontal well & $r_{w}$ & M & 0.05 \\
\hline The pore fractal dimensions & $D_{f}$ & & 1.6 \\
\hline The capillary tortuosity fractal dimensions & $D_{T}$ & & 1.2 \\
\hline Gas thickness & $H$ & $\mathrm{M}$ & 10 \\
\hline
\end{tabular}

will decrease with the increase of horizontal section length, the point, where the increasing amplitude of horizontal well net proceeds and the derivative of net proceeds to horizontal section length is zero, is the optional economical point of natural gas horizontal well, $E_{\text {opt }}$. The horizontal and vertical coordinates of this point are the economical optimal length of horizontal section, $L_{E \text { opt }}$, and the economical optimal net income, $R_{E \text { opt }}$, respectively. The economical optimal point makes sense only when the value of $R_{E \text { opt }}$ is positive. According to the actual length of horizontal well, the net income, when values of the horizontal section length are 0 and $2500 \mathrm{~m}$, is, respectively, called the initial value and final value of horizontal well net income. If the value of $R_{E \text { opt }}$ is positive and the initial value of net income is negative, the intersection point of the increasing net income line and abscissa axis is the minimum economical point of natural gas horizontal well, $E_{\min }$. The horizontal coordinate of this point is the minimum economical length of horizontal section, $L_{E \text { min }}$, which means that when the horizontal section length exceeds $L_{E \text { min }}$, the net income will no longer be a negative value and the profit space of horizontal well will exist. When $R_{E \text { opt }}$ is a positive value, and the final net income is negative, the intersection point of the decreasing net income line and the abscissa axis is the maximum economical point of natural gas horizontal well, $E_{\max }$. The horizontal coordinate of this point is the maximum economical length of horizontal section, $L_{E \max }$, which means that when the horizontal section length exceeds $L_{E \max }$, the net income becomes negative and the profit space of operation of horizontal well exists. The range between minimum economical horizontal section length $L_{E \text { min }}$, and the maximum one $L_{E \max }$ is the economical optimal range of horizontal section length. 


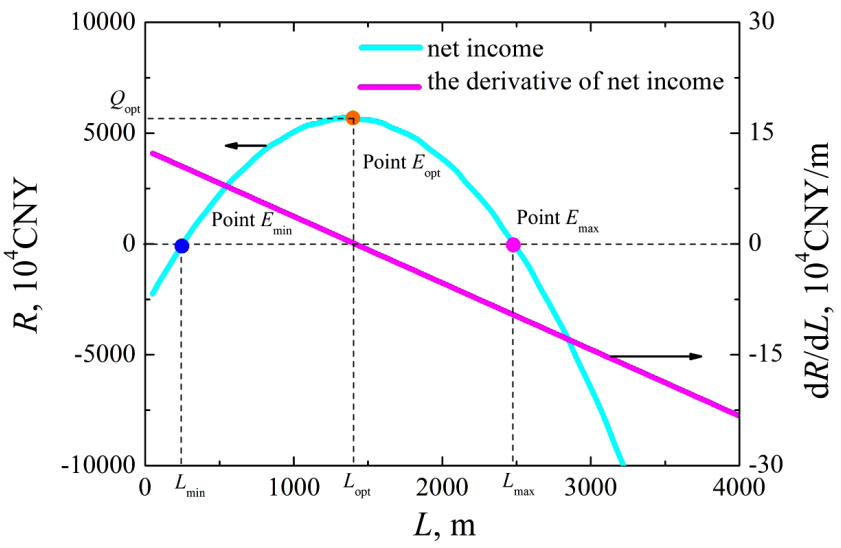

Fig. 5 The relationship between the net income and the horizontal section length of horizontal well.

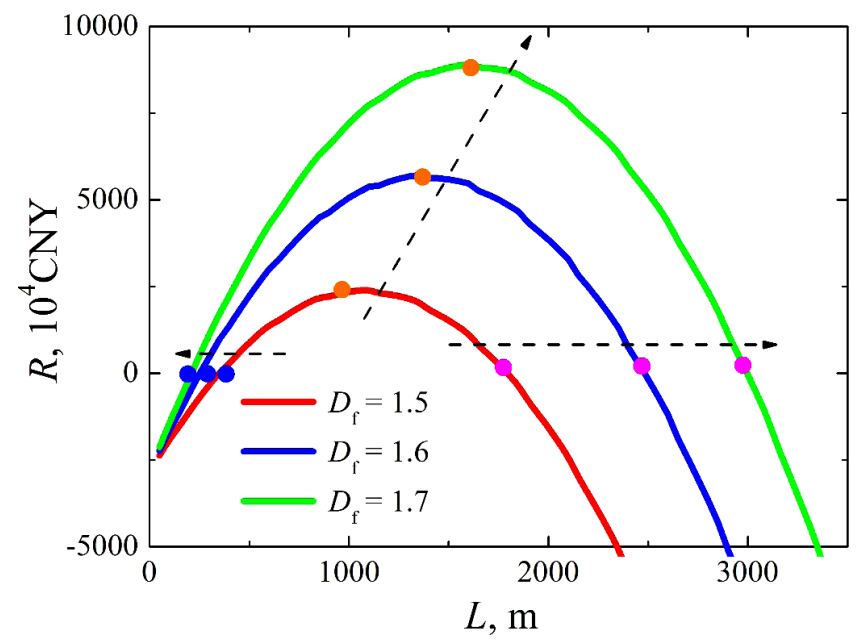

Fig. 6 Relationship between the net income and the horizontal section length in terms of different fractal dimensions of capillary radii of reservoir stratum.

What Fig. 6interprets is the relationship between net income of natural gas horizontal well and horizontal section length in terms of different fractal dimensions of capillary radius of reservoir stratum. Draw the relationship curve of net proceeds and the horizontal section length when other parameters are fixed, and the fractal dimension of different capillary radii of reservoir stratum is $1.5,1.6$ and 1.7, respectively. It should be observed from Fig. 6 with the gradual increase of the fractal dimension of reservoir stratum capillary radius, the relationship curve of net proceed and horizontal section length moves constantly to the upper right, minimum economical point of horizontal well shifts to the left, the maximum one to the right and the optimal one to the upper right. According to the formula of the capillary radius fractal dimension, the greater the fractal dimension value is, the more the number of capillaries of a greater radius in unit crosssection of reservoir stratum will be, which means a greater area of seepage channel for the gas leads to a greater open-flow capacity of gas. The porosity $C_{\mathrm{md}}$ absolute permeability of reservoir stratum increases with the increment of fractal dimension of capillary radius, so that the open-flow capacity of gas increases macroscopically. Thus, the production conditions of natural gas horizontal well are enhanced as the fractal dimension of capillary radius of reservoir stratum increases, resulting in a broader optimal range of horizontal section length, a longer optimal economical horizontal section and a bigger profit space of horizontal well operation.

What Fig. 7 depicted is the relationship between the net proceeds of natural gas horizontal well and the horizontal section length with respect to different capillary tortuosity fractal dimensions of reservoir stratum. Draw the relationship curve of net proceeds and the capillary tortuosity fractal dimension of reservoir stratum; they are 1.1, 1.2 and 1.3, respectively. It is obviously reflected in Fig. 7 that with a gradual increment of the capillary tortuosity fractal dimension of reservoir stratum, the relationship curve of net proceeds and horizontal section length moves constantly forwards the lower left, the minimum economical point shifts to the right, the maximum one to the left and the optimal one to the lower left. What is a responsible tortuosity fractal dimension of reservoir stratum leads to a greater capillary curvature and a bigger pressure loss of gas flowing in the capillary of reservoir, which means

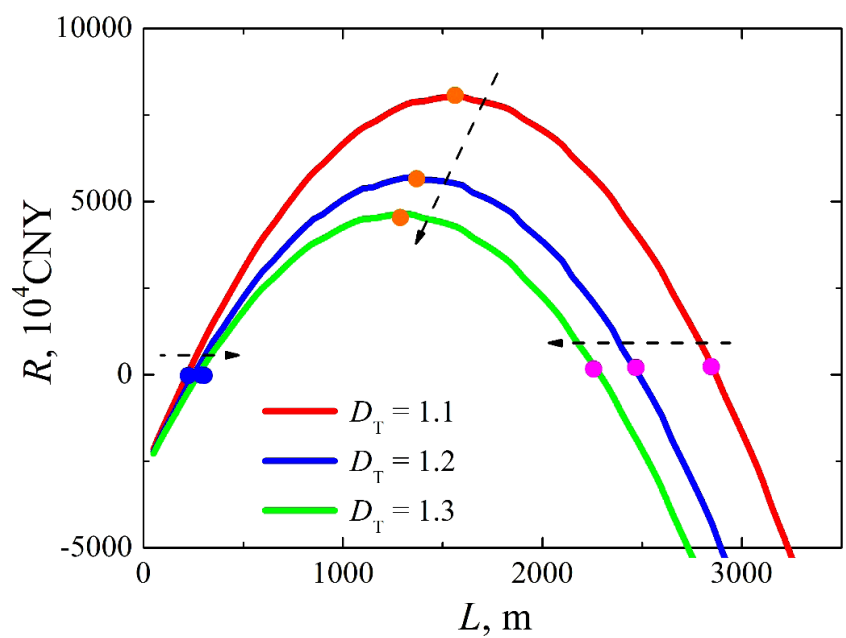

Fig. 7 Relationship between the net proceeds of natural gas horizontal well and the horizontal section length with respect to different capillary tortuosity fractal dimensions of reservoir stratum. 
a smaller gas volume flowing through the capillary per unit time leads to a smaller open-flow capacity of gas. As for horizontal well, the percolation capacity of formation means that the gas well will decrease with a too large capillary tortuosity fractal dimension of reservoir, resulting in the decrease of well productivity. This image indicates that the increase of capillary tortuosity fractal dimension of reservoir contributes to a narrower optimal range of horizontal section length, a shorter optimal economical horizontal section and a smaller profit space of horizontal well operator, which makes it difficult to obtain greater economic benefits.

\section{CONCLUSIONS}

In this work, the previous researches for NPV of horizontal well are reviewed. The fractal analysis is presented for NPV of MHFHW, based on the fractal expressions of formation parameters. The new fractal model is established and solved, type curves are illustrated and the behavior characteristics are analyzed. With the aid of apparent permeability model, a pseudo pressure expression considering both reservoir fractal features and slippage effect is derived, contributing to establish the productivity model. Type curves are dominated by fractal parameters that affect type curves differently. The fractal dimensions $D_{f}$ and the capillary tortuosity fractal dimensions $D_{T}$ have significant effects on the NPV of a MHFHW. Finally, the proposed model in this paper provides a new methodology for analyzing and predicting the NPV of an MHFHW. The proposed model gives a new way to optimize the design of MHFHW.

\section{ACKNOWLEDGMENTS}

This work is supported by PetroChina Innovation Foundation (2016D-5007-0209).

\section{REFERENCES}

1. H.-M. Petit, G. Renard and E. Valentin, Technical and economic evaluation of steam injection with horizontal well for two typical heavy-oil reservoirs, in SPE Annual Technical Conference and Exhibition (Society of Petroleum Engineers, 1989).

2. G. Guo and R. Evans, An economic model for assessing the feasibility of exploiting naturally fractured reservoirs by horizontal well technology, in $S P E$ Annual Technical Conference and Exhibition (Society of Petroleum Engineers, 1993).
3. J. Smith, M. Economides and T. Frick, Reducing economic risk in areally anisotropic formations with multiple-lateral horizontal wells, in SPE Annual Technical Conference and Exhibition (Society of Petroleum Engineers, 1995).

4. T. Frauenfeld, D. Lillico, C. Jossy, G. Vilcsak, S. Rabeeh and S. Singh, Evaluation of partially miscible processes for Alberta heavy oil reservoirs, J. Can. Petrol. Technol. 37 (1998) 21-24.

5. D. Komery, R. Luhning and J. O'rourke, Towards commercialization of the UTF project using surface drilled horizontal SAGD wells, J. Can. Petrol. Technol. 38 (1999) 36-43.

6. H. Cho, Integrated optimization on long horizontal well length, in SPE Hydrocarbon Economics and Evaluation Symposium (Society of Petroleum Engineers, 2001).

7. N. Edmunds and H. Chhina, Economic optimum operating pressure for SAGD projects in Alberta, J. Can. Petrol. Technol. 40 (2001) 13-17.

8. J. D. Wright, Economic evaluation of shale gas reservoirs, in SPE Shale Gas Production Conference (Society of Petroleum Engineers, 2008).

9. L. K. Britt and M. B. Smith, Horizontal well completion, stimulation optimization, and risk mitigation, in SPE Eastern Regional Meeting (Society of Petroleum Engineers, 2009).

10. C. Yang, C. Card and L. Nghiem, Economic optimization and uncertainty assessment of commercial SAGD operations, J. Can. Petrol. Technol. 48 (2009) 33-40.

11. B. Bagherian, A. Ghalambor, M. Sarmadivaleh, V. Rasouli, A. Nabipour and M. M. Eshkaftaki, Optimization of multiple-fractured horizontal tight gas well, in SPE International Symposium and Exhibiton on Formation Damage Control (Society of Petroleum Engineers, 2010).

12. E. E. Mendoza, J. Aular and L. J. Sousa, Optimizing horizontal-well hydraulic-fracture spacing in the eagle ford formation, Texas, in North American Unconventional Gas Conference and Exhibition (Society of Petroleum Engineers, 2011).

13. M. J. Kaiser, Profitability assessment of Haynesville shale gas wells, Energy 38 (2012) 315-330.

14. M. J. Kaiser, Haynesville shale play economic analysis, J. Petrol. Sci. Eng. 82 (2012) 75-89.

15. G. Gülen, J. Browning, S. Ikonnikova and S. W. Tinker, Well economics across ten tiers in low and high Btu (British thermal unit) areas, Barnett Shale, Texas, Energy 60 (2013) 302-315.

16. B. Yu and P. Cheng, A fractal permeability model for bi-dispersed porous media, Int. J. Heat Mass Transf. 45 (2002) 2983-2993.

17. E. Perfect, Modeling the primary drainage curve of prefractal porous media, Vadose Zone J. 4 (2005) 959-966. 
18. A. Cihan, J. S. Tyner and E. Perfect, Predicting relative permeability from water retention: A direct approach based on fractal geometry, Water Resour. Res. 45 (2009).

19. A. Cihan, M. C. Sukop, J. S. Tyner, E. Perfect and H. Huang, Analytical predictions and lattice Boltzmann simulations of intrinsic permeability for mass fractal porous media, Vadose Zone J. 8 (2009) 187196.

20. D. Shou, J. Fan and F. Ding, A difference-fractal model for the permeability of fibrous porous media, Phys. Lett. A 374 (2010) 1201-1204.

21. J.-W. Kim, M. C. Sukop, E. Perfect, Y. A. Pachepsky and H. Choi, Geometric and hydrodynamic characteristics of three-dimensional saturated prefractal porous media determined with lattice Boltzmann modeling, Transp. Porous Media 90 (2011) 831-846.

22. D. Shou, J. Fan and F. Ding, Hydraulic permeability of fibrous porous media, Int. J. Heat Mass Transf. 54 (2011) 4009-4018.

23. B. Xiao, J. Fan and F. Ding, A fractal analytical model for the permeabilities of fibrous gas diffusion layer in proton exchange membrane fuel cells, Electrochim. Acta 134 (2014) 222-231.

24. P. Xu, B. Yu, X. Qiao, S. Qiu and Z. Jiang, Radial permeability of fractured porous media by Monte Carlo simulations, Int. J. Heat Mass Transf. 57 (2013) 369-374.

25. P. Xu, S. Qiu, B. Yu and Z. Jiang, Prediction of relative permeability in unsaturated porous media with a fractal approach, Int. J. Heat Mass Transf. 64 (2013) 829-837.

26. X.-H. Tan, X.-P. Li, J.-Y. Liu, C. Tang and J.-M. Li, Pressure transient analysis of dual fractal reservoir, J. Appl. Math. 2013 (2013) 137518.

27. X.-H. Tan, J.-Y. Liu, J.-H. Zhao, X.-P. Li, G.-D. Zhang and C. Tang, A pressure transient model for power-law fluids in porous media embedded with a tree-shaped fractal network, Math. Probl. Eng. 2014 (2014) 8.

28. X.-H. Tan, X.-P. Li, J.-Y. Liu, G.-D. Zhang and L.-H. Zhang, Analysis of permeability for transient two-phase flow in fractal porous media, J. Appl. Phys. 115 (2014) 113502.

29. J. Cai and B. Yu, A discussion of the effect of tortuosity on the capillary imbibition in porous media, Transp. Porous Media 89 (2011) 251-263.

30. J. Cai, X. Hu, D. C. Standnes and L. You, An analytical model for spontaneous imbibition in fractal porous media including gravity, Colloids Surf. A 414 (2012) 228-233.

31. M. Yun, B. Yu, P. Xu and J. Cai, Fractal analysis of power-law fluid in a single capillary, Chin. Phys. Lett. 25 (2008) 616.
32. M. Yun, B. Yu and J. Cai, A fractal model for the starting pressure gradient for Bingham fluids in porous media, Int. J. Heat Mass Transf. 51 (2008) 1402-1408.

33. Y. Li and B. Yu, Study of the starting pressure gradient in branching network, Sci. China Technol. Sci. 53 (2010) 2397-2403.

34. B. Xiao, Y. Yang and L. Chen, Developing a novel form of thermal conductivity of nanofluids with Brownian motion effect by means of fractal geometry, Powder Technol. 239 (2013) 409-414.

35. P. Xu, B. Yu, Y. Feng and Y. Liu, Analysis of permeability for the fractal-like tree network by parallel and series models, Phys. A: Stat. Mech. Appl. 369 (2006) 884-894.

36. L. Gosselin, Optimization of tree-shaped fluid networks with size limitations, Int. J. Therm. Sci. 46 (2007) 434-443.

37. X.-H. Tan and X.-P. Li, Transient flow model and pressure dynamic features of tree-shaped fractal reservoirs, J. Hydrodyn. Ser. B 26 (2014) 654663.

38. J. Cai, A fractal approach to low velocity non-Darcy flow in a low permeability porous medium, Chin. Phys. B 23 (2014) 044701.

39. Y.-L. Zhao, L.-H. Zhang, J.-Z. Zhao, J.-X. Luo and B.-N. Zhang, "Triple porosity" modeling of transient well test and rate decline analysis for multi-fractured horizontal well in shale gas reservoirs, J. Petrol. Sci. Eng. 110 (2013) 253-262.

40. H. T. Wang, Performance of multiple fractured horizontal wells in shale gas reservoirs with consideration of multiple mechanisms, J. Hydrol. 510 (2014) 299-312.

41. M. Muskat and M. W. Meres, The flow of heterogeneous fluids through porous media, J. Geol. 7 (1938) $346-363$.

42. Q. Zheng, B. Yu, Y. Duan and Q. Fang, A fractal model for gas slippage factor in porous media in the slip flow regime, Chem. Eng. Sci. 87 (2013) 209215.

43. W. C. Krumbein, The Flow of Homogeneous Fluids Through Porous Media by M. Muskat (McGraw-Hill Book Co., Inc., 1937).

44. R. Al-Hussainy and H. J. Ramey Jr, Application of real gas flow theory to well testing and deliverability forecasting, J. Petrol. Technol. 18 (1966) 637642.

45. R. Al-Hussainy, H. J. Ramey Jr and P. B. Crawford, The flow of real gases through porous media, J. Petrol. Technol. 18 (1966) 624-636.

46. X.-H. Tan, J.-Y. Liu, X.-P. Li, L.-H. Zhang and J. Cai, A simulation method for permeability of porous media based on multiple fractal model, Int. J. Eng. Sci. 95 (2015) 76-84. 